\title{
Healthcare utilization and monetary costs associated with agitation in UK care home residents with advanced dementia: a prospective cohort study
}

\author{
A. Buylova Gola, ${ }^{1}$ S. Morris, ${ }^{2}$ B. Candy, ${ }^{1}$ S. Davis, ${ }^{1}$ M. King, ${ }^{3}$ N. Kupeli, ${ }^{1}$ G. Leavey, ${ }^{4}$ \\ K. Moore, (1) I. Nazareth, ${ }^{5}$ R. Omar, ${ }^{6}$ V. Vickerstaff,, ${ }^{1,5}$ L. Jones, ${ }^{1}$ and E. L. Sampson, ${ }^{1,7}$ \\ ${ }^{1}$ Marie Curie Palliative Care Research Department, Division of Psychiatry, University College London, London, United Kingdom \\ ${ }^{2}$ Department of Applied Health Research, University College London, London, United Kingdom \\ ${ }^{3}$ Division of Psychiatry, University College London, London, United Kingdom \\ ${ }^{4}$ The Bamford Centre for Mental Health and Well Being, Ulster University, Northern Ireland \\ ${ }_{5}^{5}$ Department of Primary Care and Population Health, University College London, London, United Kingdom \\ ${ }^{6}$ Department of Statistical Science, University College London, London, United Kingdom \\ ${ }^{7}$ Barnet Enfield and Haringey Mental Health Trust Liaison Psychiatry Team, North Middlesex University Hospital, London, United Kingdom
}

Objective: Nearly half of care home residents with advanced dementia have clinically significant agitation. Little is known about costs associated with these symptoms toward the end of life. We calculated monetary costs associated with agitation from UK National Health Service, personal social services, and societal perspectives.

Design: Prospective cohort study.

Setting: Thirteen nursing homes in London and the southeast of England.

Participants: Seventy-nine people with advanced dementia (Functional Assessment Staging Tool grade 6e and above) residing in nursing homes, and thirty-five of their informal carers.

Measurements: Data collected at study entry and monthly for up to 9 months, extrapolated for expression per annum. Agitation was assessed using the Cohen-Mansfield Agitation Inventory (CMAI). Health and social care costs of residing in care homes, and costs of contacts with health and social care services were calculated from national unit costs; for a societal perspective, costs of providing informal care were estimated using the resource utilization in dementia (RUD)-Lite scale.

Results: After adjustment, health and social care costs, and costs of providing informal care varied significantly by level of agitation as death approached, from $£ 23,000$ over a 1-year period with no agitation symptoms (CMAI agitation score $0-10$ ) to $£ 45,000$ at the most severe level (CMAI agitation score $>100$ ). On average, agitation accounted for $30 \%$ of health and social care costs. Informal care costs were substantial, constituting $29 \%$ of total costs.

Conclusions: With the increasing prevalence of dementia, costs of care will impact on healthcare and social services systems, as well as informal carers. Agitation is a key driver of these costs in people with advanced dementia presenting complex challenges for symptom management, service planners, and providers.

Key words: nursing homes, healthcare costs, social care costs, economics

\section{Introduction}

It is estimated that 46.8 million people have dementia worldwide. This number is expected to treble by

Correspondence should be addressed to: Anna Buylova Gola, Marie Curie Palliative Care Research Department, Division of Psychiatry, University College London, 6th Floor, Maple House, 149 Tottenham Court Road, London W1T 7NF, United Kingdom. Phone + 0207 6799720. Fax: + 0207 6799024. E-mail: anna .gola@ucl.ac.uk. Received 29 Aug 2019; revision requested 22 Sep 2019; revised version received 21 Nov 2019; accepted 29 Nov 2019. First published online 17 January 2020.
2050 (Prince et al., 2015). The Dementia UK report (Alzheimer's Society, 2014) estimates that 1 in every 14 of the population aged 65 years and over has some form of dementia.

While in national records many deaths were not directly attributed to dementia, but to the immediate cause of death (NCPC, 2015), it has been estimated that in England and Wales over the period 20062014, annual deaths associated with dementia have increased more than twofold, from 27,364 to 59,199 
(Etkind et al., 2017) and accounted for $12 \%$ of all deaths registered in 2016 (ONS, 2016). The prevalence of dementia increases with age and the median length of survival from diagnosis to death is estimated to be around 4.1 years, although people can live much longer (Rizzuto et al., 2012) and the trajectory of decline and survival length may be difficult to predict (Sampson et al., 2017). People with dementia (PWD) are more likely to die in a care home or hospital (Handley et al., 2014) than anywhere else (Sleeman et al., 2014).

It is estimated that $37 \%$ of all PWD in the UK are in long-term care institutions costing the social care system in excess of $£ 9 \mathrm{bn} /$ year (Prince et al., 2014). The prevalence of dementia in care homes has risen from $56 \%$ in 2002 to $70 \%$ in 2013 (Matthews et al., 2013). The Health Economics Research Centre in Oxford (2010) put the healthcare costs associated with dementia at $£ 1.2 \mathrm{bn} /$ annum of which hospital inpatient stays account for $44 \%$ of the total (Alzheimer's Research Trust, 2010). The economic burden of dementia is far greater than cancer, chronic heart disease (CHD), and stroke. Recent estimates suggest that dementia has higher health and social care costs $(£ 11.9 \mathrm{bn} / \mathrm{annum})$ than cancer $(£ 5.0 \mathrm{bn})$ and chronic heart disease $(£ 2.5 \mathrm{bn})$ combined (Luengo-Fernandez et al., 2015).

Little is known about the costs associated with dementia when dementia has progressed to the advanced stages. Alzheimer's Disease International (2010) estimated that the total annual cost per person with advanced dementia residing in a care home is $£ 31,296$ with the majority (69\%) of costs associated with institutional care itself, while $18 \%$ being accounted by inpatient and outpatient care and $11 \%$ by primary care service use (Alzheimer's Disease International 2010). Prince et al. (2014) estimated that most dementia costs per year are due to informal care at $£ 11.6$ bn $(44.2 \%)$, with social care costs $£ 10.3$ bn (39.0\%) and healthcare costs $£ 4.3$ bn (16.4\%). Moreover, for people living in a residential care setting, the average annual cost per person in the mild stages of dementia is $£ 31 \mathrm{k}$, for people in the moderate stages is $£ 38 \mathrm{k}$, and for people in the severe stages is $£ 37 \mathrm{k}$. A few studies have found that increased dementia severity is associated with higher costs (Wolstenholme et al., 2002; Livingston et al., 2004).

Over $70 \%$ of PWD experience significant levels of agitation, the most common neuropsychiatric symptom (Jakobson et al., 2015). This results in lower quality of life and adds to the burden of carers (Livingston et al., 2017), and may trigger agitation in other residents (Ridder et al., 2013), as well as significantly increases costs of care. Morris et al. (2015) concluded that agitation in people with Alzheimer's disease has substantial monetary burden in excess of the costs associated with cognitive impairment, amounting to the mean excess cost of $£ 4091$ a year, accounting for $12 \%$ of the health and social care costs, but data on how costs are distributed in people with advanced dementia are unavailable. Outside of the UK, the evidence on the relationship between progression of dementia and associated healthcare costs based on longitudinal datasets appears inconclusive (Konig et al., 2014; Leicht et al., 2013).

The aim of our study was to conduct a comprehensive cost analysis, including health and social care costs, to calculate the monetary costs associated with agitation in care home residents with advanced dementia. Even when PWD resides in care homes, unpaid carers often provide essential support and care and their contribution to care needs to be recognized and valued.

\section{Methods}

\section{Setting of cohort study}

We recruited people with advanced dementia residing in nursing homes from six UK primary care clinical commissioning groups (CCGs - local health planning and delivery organizations) across London and South East England. We purposively selected at least one nursing home from each CCG ensuring a representative range of Care Quality Commission ratings (a UK statutory body which regulates the quality of care), Gold Standards Framework (2008) implementation level (a UK national program to improve end-of-life care), number of beds, and ownership (private/voluntary sector), encompassing socioeconomic and ethnic diversity. To ensure access to primary care data, participants were registered with general practices linked to the Primary Care Research Network. Data were collected in May 2012-December 2014. Monetary costs were calculated from a National Health Service and personal social services perspective for all residents and from a societal perspective for resident/informal carer dyads where present.

\section{Inclusion and exclusion criteria}

We recruited people with a clinical diagnosis of dementia (DSM-IV criteria), aged over 65 years, who were at Functional Assessment Staging Tool (FAST) grade 6e and above (Reisberg, 1998) (one of: doubly incontinent and speaks only a few words, unable to walk, all intelligible speech is lost, unable to smile, unable to hold their head up). Informal carers (subsequently referred to as "carers") approached for participation included family members or friends in regular contact with the person with dementia, usually the next of kin or a key decision 
maker. Carers were able to speak sufficient English to complete questionnaires. Recruitment and consent procedures are detailed in Jones et al. (2012)

\section{Study measures}

All outcomes were measured at study entry and then every 4 weeks for a maximum of 9 months or until the person with dementia died. We used a pragmatic approach to collect as much data as possible from a range of sources: informal carers, care home staff, and program researchers.

\section{Primary outcomes}

The Client SeRvice ReCeipt inventory

The Client Service Receipt Inventory (CSRI; Beecham and Knapp, 1992) measures the services consumed, and details of housing at a care home sufficient to permit costing. It has been amended for use in older people incorporating contacts with health and social care services (general practitioner (GP), practice nurse at the GP surgery, district nurse at the person's home, dietician, community psychiatric nurse, physiotherapist, chiropodist, optician, dentist, audiologist, psychologist, psychiatrist, hospital outpatient visits, and inpatient stays). Specific fee details for individual care home accommodation are also recorded in CSRI.

\section{RUD-LITE}

Supplementary service use data were available from resource utilization in dementia (RUD)-Lite, a resource utilization questionnaire adapted specifically for PWD (Wimo and Winblad, 2003). Completed by carers, it assesses the time carers spend on the provision of informal care regarding activities of daily living and instrumental activities of daily living, carer work status, and carer's resource utilization.

CoHEN-MANSFIELD AGITATION INVENTORY Agitation was assessed by the program researcher or care home staff using the Cohen-Mansfield Agitation Inventory (CMAI) (Cohen-Mansfield et al., 1989), a rating questionnaire consisting of 29 agitated behaviors. It assesses agitated behaviors in PWD in long-term care settings. These can be generalized into wandering, physical aggressions, inappropriate vocalizations, hoarding items, sexual disinhibition, and negativisms. A seven-point rating system is used to judge the frequency of the 29 behaviors ranging from 1, the participant never engages in the specific agitated behavior to 7 , the participant manifests the behavior several times an hour. Thus, the maximum score is 203 . Responses are based on observation of the individual. A score of over 39 is considered clinically significant agitation (Livingston et al., 2017).

\section{Other outcomes}

For PWD, we also collected data on: prescribing (type of medication and indication, daily dose and duration), Charlson comorbidity Index (Charlson, 1987), sentinel events (acute changes in a person's condition, i.e. a fall or hospital admission), pain (Pain Assessment in Advanced Dementia scale [PAINAD] [Warden et al., 2003]), quality of life (Quality of Life in LateStage Dementia Scale [QUALID] [Weiner et al., 2000]), Symptom Management at the End of Life in Dementia Scale (SM-EOLD) (Kiely et al., 2006), and mortality. Questionnaires were completed by the visiting research team, or in consultation with the care home staff and carers if they were present at the time. More details on data collection process and other outcome measures not used here are available separately (Sampson et al., 2017; Moore et al., 2017).

\section{Cost estimation}

A failure to incorporate costs of informal care risks undervaluing the total cost of care. Total societal costs were evaluated using an opportunity cost approach taking into account productivity loss for working informal carers and lost leisure time for nonworking carers. Costs were calculated for the month before each visit. Total societal costs were calculated by combining direct costs, consisting of PWD healthcare costs (including medications, hospitalizations, and outpatient visits) and social care costs (including community care services), and indirect costs, consisting of carer informal care costs (including the time spent giving care and missing work). Most clinical outcome measures were measured at a single time point, while others were measured over a period of time, such as over the preceding 1 week for CMAI and preceding 4 weeks for the CSRI and RUD-Lite. To address this, we calculated a 4-week moving average in assigning calculated unadjusted mean costs by a CMAI score.

Health and social care services used were estimated using national unit costs data from routine sources (Curtis, 2012; Department of Health, 2013). All hospital services, day services, medications, and the time of community-based professionals were costed this way. We applied unit costs from routine sources in 2012 UK£ and extrapolated them to a 12 -month period (for those still alive after the final 9-month follow-up). As the majority $(64 \%)$ of the care home residents were still alive after the final follow-up at 9 months and accounting for an average of further $12 \%$ of residents deceased each month for 3 months, we obtained 12-month monetary costs which are more illustrative in the subsequent analysis of predicting costs of long-term care. We assumed that costs remained constant throughout the year. 
Costs relating to paramedic callouts have not been estimated, assuming that the majority are incorporated in hospital visit calculations. While some paramedic calls might have not resulted in a hospitalization, it is difficult to estimate the type of care a resident might have received in those cases. For the purposes of costing, we assumed that some visits were face to face (e.g. GPs, physiotherapists, OTs, district nurses), while others were either consultant or non-consultant led with equal probability (e.g. geriatrician, psychiatrist). Data on the costs of care home stay were provided by care homes.

For the extended analysis of monetary burden of advanced dementia from a societal perspective (accounting for informal care provision: time spent performing general tasks, specific tasks, and supervisory activities) for 35 dyads, carers' productivity losses were assessed using the RUD-Lite, in which employed carers were asked to state whether they had reduced or quit their work and, if so, for how many hours they had reduced their work during the last 30 days. Details of carers' employment were also contained in RUD-Lite. We have applied an opportunity cost approach (van den Berg et al., 2004), by monetarily valuing (a) lost production using the average hourly gross wage plus nonwage labor costs and (b) lost leisure time using the average hourly net wage plus unemployment and pension insurance contributions. If a carer has reduced working time or terminated employment to provide informal care, the assessed informal carer's time was reduced by carer's assessed lost production time to avoid double-counting informal care cost. Employment earnings data by occupation were obtained from the Office for National Statistics (Annual Survey of Hours and Earnings, 2013).

\section{Statistical analyses}

We calculated descriptive statistics for residents and recorded resource use. The median monthly followup was 9 for those still alive (interquartile range $[\mathrm{IQR}]=8-9$ ) and for those that died, the median number of follow-ups was 4 (IQR $=2.5-6.5)$. Thirty-eight percent of participants died during the study and by assuming that a further $12 \%$ of residents will die in the months $10-12$ with roughly $4 \%$ each month, we have extrapolated 12 -month health and social care mean costs by applying mean costs from the residents deceased in a preceding month within the study period. For patients who were assumed to have died in the months 10-12, last observation carried forward was assumed such that costs and CMAI scores from the last known visit were extrapolated up to the date of assumed death (no costs after assumed death were computed).
For patients that were assumed to remain alive during the months $10-12$, the multiple imputation regression method (Rubin, 1987) stratified by CMAI was applied to generate costs. Mean costs were applied, as interquartile ranges were often unavailable for costs of particular hospital admissions.

With a score of over 39 clinically considered indicative of agitation on the CMAI scale we calculated unadjusted mean costs using a dichotomous score $(\leq 39,>39)$ to examine between-group differences using one-way analysis of variance and the Mann-Whitney two-sample test. We calculated pairwise correlations of CMAI with other outcomes indicative of psychological symptoms (PAINAD, SM-EOLD, number of sentinel events) and quality of life (QUALID) at baseline. We used a multilevel random effects regression model to assess these correlations over the nine follow-up time points, taking into account the repeated measures.

We had 576 data points (person follow-ups) with the total CMAI score ranging from 7 to 107 with 66 unique values, and we have grouped scores into bands of 10 resulting in 11 categories and repeated the analysis as when the score was considered a dichotomous variable.

Adjustments were made for total CMAI score at each time point and follow-up (repeated sampling). We examined the association between dichotomous CMAI score and other potential confounders (age, gender, and marital status) using Chi square tests. In addition, use of health and social services may be greater among those with more significant cognitive and physical problems. All participants had advanced dementia and it was not possible to assess decline because of floor effects on the FAST (Reisberg, 1998). Chronic comorbidities were included as an additional possible confounder (Charlson index).

To account for cost data skewness in analyzing the association between costs and sociodemographic as well as clinical variables, we applied a generalized linear model (gamma family) with a log link (Thompson and Barber, 1999). Due to the highly skewed distribution of healthcare costs, standard errors and confidence intervals were estimated by bootstrapping (Desgagne et al., 1998) with 1000 replications. Analyses was conducted in STATA 13 (StataCorp, 2014).

\section{Ethics}

We used the UK 2005 Mental Capacity Act to determine capacity for consent. For those without a personal or a nominated "professional", we used a consultee to give agreement (National Research Ethics Committee East of England approval 12/ $\mathrm{EE} / 0003)$. 
Table 1. Physical and psychological symptoms, quality of life in people with advanced dementia $(n=79)$ variable

\begin{tabular}{|c|c|c|c|c|}
\hline & $\begin{array}{c}\text { STUDY } \\
\text { ENTRY }(n=79)\end{array}$ & $\begin{array}{l}\text { FINAL VISIT } \\
(\text { IF ALIVE) } \\
\quad(n=49)^{\mathrm{a}}\end{array}$ & $\begin{array}{l}\text { FINAL VISIT } \\
\quad(\text { IF DIED }) \\
\quad(n=28)\end{array}$ & $\begin{array}{l}\text { FINAL VISIT } \\
\text { (ALL PWD) } \\
\quad(n=77)\end{array}$ \\
\hline \multicolumn{5}{|l|}{ PAINAD: $(n, \%)$} \\
\hline Rest (score 2+) & $8(10)$ & $9(18)$ & $4(14)$ & $13(17)$ \\
\hline Movement (score $2+$ ) & $48(61)$ & $27(60)$ & $15(54)$ & $42(58)$ \\
\hline CMAI: behavioral disturbances $(39+)$ & $44(56)$ & $28(57)$ & $14(50)$ & $42(55)$ \\
\hline Mean (SD) & $45.8(16.7)$ & $45.5(17.8)$ & $41.8(13.3)$ & $44.2(16.3)$ \\
\hline \multicolumn{5}{|l|}{ Sentinel events, $n(\%)$} \\
\hline Difficulty swallowing & $34(43)$ & $29(60)$ & $16(59)$ & $45(60)$ \\
\hline Breathing difficulties & $15(19)$ & $10(20)$ & $14(50)$ & $24(31)$ \\
\hline Urinary tract infection & $12(15)$ & $4(8)$ & $4(15)$ & $8(11)$ \\
\hline Pneumonia & $3(4)$ & $1(2)$ & $4(15)$ & $5(7)$ \\
\hline Fever & $1(1)$ & $2(4)$ & $1(4)$ & $3(4)$ \\
\hline \multicolumn{5}{|l|}{ QUALID } \\
\hline Median (IQR) & $24(20-29)$ & $24(20-28)$ & $26(21-30)$ & $24(20-28)$ \\
\hline Mean (SD) & $25.0(6.0)$ & $24.2(5.4)$ & $26.5(7.0)$ & $25.0(6.0)$ \\
\hline \multicolumn{5}{|l|}{ SM-EOLD } \\
\hline Median (IQR) & $30(22-35)$ & $26(20-34)$ & $28(23-32)$ & $27(20-32)$ \\
\hline Mean (SD) & $28.4(8.3)$ & $26.3(8.2)$ & $26.8(6.3)$ & $26.4(7.5)$ \\
\hline
\end{tabular}

PAINAD, Pain Assessment in Advanced Dementia; CMAI, Cohen-Mansfield Agitation Inventory; SD, standard deviation; IQR, interquartile range; QUALID, Quality of Life in Late-Stage Dementia Scale; SM-EOLD, Symptom Management at the End of Life in Dementia Scale.

${ }^{a}$ Two participants were alive at the end of follow-up but data were not available, one participant was admitted to hospital and another moved away.

\section{Results}

\section{People with dementia}

We recruited 79 care home residents with advanced dementia; most were female and White British. On average, prior to commencement of the study, they had spent 3 years in a care home, with roughly equal proportions being admitted to a care home from a private home $(30 \%)$, acute hospital $(28 \%)$, and residential or other nursing home (34\%). Characteristics of residents are presented in Table 1.

\section{Carers}

Sixty-one carers of the PWD were identified, 26 refused to participate, and 1 carer withdrew during the study period, forming a subsample of 35 dyads (i.e. participant and their carer). Carers were mostly female $(69 \%)$, with a median age of 62 years (IQR = 54-69) and son/daughter (71\%) or spouse/partner $(20 \%)$ of the person with dementia.

\section{Health and social care costs}

Many people with advanced dementia are at the end of life and 31 died during the 9-month follow-up out of 79. Our data have 577 data points (person follow-ups). The mean CMAI score throughout the study is 45.5 (SD 16.5, range 7-107). The majority of residents
(55\%) had significant agitation (CMAI score $>39$, Table 2) throughout the study period.

When applying the unit costs to the resource data, unadjusted mean (95\% CI) costs per resident with agitation $\leq 39$ and $>39$ were $£ 25,427$ ( $£ 15,766$; $£ 35,088)$ and $£ 34,970 \quad(£ 18,541 ; £ 51,381)$, respectively.

Cost data were highly skewed and increased with CMAI score. The skewness is partially explained by a minority of patients having numerous repeated hospital admissions and input from other healthcare professionals.

The primary driver of costs was care home accommodation ( $48 \%$ of the total costs). Hospital admissions accounted for $28 \%$ of the overall costs and over a half of the costs associated with service use alone (excluding care home housing).

In the analysis adjusted for effects of clustering by repeated measures within participants (Table 2 and Figure 1), mean costs ranged by CMAI scores from $£ 23,154(£ 11,447 ; £ 34,861)$ with none or few agitation symptoms to $£ 44,868(£ 24,781 ; £ 64,954)$ at the most severe level (CMAI score >100). While a linear relationship is evident up to the score of around 50, there is a seesaw pattern at the higher ranges. Unadjusted analysis yielded similar findings.

While costs varied significantly by the CMAI score, there was no statistically significant variation 
Table 2. Association between symptoms of agitation and annual cost ${ }^{\mathrm{a}}$ per patient: unadjusted and adjusted $^{\mathrm{b}}$ analyses (participants $=79$ )

\begin{tabular}{|c|c|c|c|}
\hline CMAI AGITATION SCORE & NUMBER ${ }^{c}(\%)$ & MEAN $(95 \% \mathrm{CI})$ & ADJUSTED MEAN (95\% CI) \\
\hline \multicolumn{4}{|c|}{ Health and social care perspective $\left(n^{\mathrm{c}}=577\right)$} \\
\hline$\leq 39$ & $261(45)$ & $25,427(15,766 ; 35,088)$ & $26,712(17,577 ; 35,847)$ \\
\hline$>39$ & $316(55)$ & $34,970(18,541 ; 51,381)$ & $35,790(22,068 ; 49,532)$ \\
\hline $0-10$ & $4(0.69)$ & $21,180(10,075 ; 32,284)$ & $23,154(11,447 ; 34,861)$ \\
\hline $11-20$ & 0 & $23,154(11,447 ; 34,861)$ & $22,583(12,813 ; 32,353)$ \\
\hline $21-30$ & $125(21.67)$ & $26,270(16,241 ; 36,290)$ & $29,557(13,150 ; 45,964)$ \\
\hline $31-40$ & $139(24.09)$ & $29,736(23,490 ; 35,972)$ & $34,787(24,140 ; 45,434)$ \\
\hline $41-50$ & $114(19.75)$ & $35,206(18,138 ; 52,275)$ & $42,211(19,273 ; 65,149)$ \\
\hline $51-60$ & $93(16.12)$ & $32,236(27,729 ; 34,943)$ & $31,829(752 ; 63,806)$ \\
\hline $61-70$ & $49(8.49)$ & $28,539(12,095 ; 45,073)$ & $27,139(16,207 ; 38,071)$ \\
\hline $71-80$ & $33(5.72)$ & $23,741(16,087 ; 29,655)$ & $23,812(8099 ; 39,712)$ \\
\hline $81-90$ & $12(2.08)$ & $42,275(19,719 ; 64,831)$ & $41,236(6628 ; 75,844)$ \\
\hline $91-100$ & $6(1.04)$ & $28,615(15,467 ; 41,763)$ & $29,491(17,018 ; 41,765)$ \\
\hline $101-107$ & $2(0.34)$ & $46,674(12,515 ; 89,616)$ & $44,868(24,781 ; 64,954)$ \\
\hline \multicolumn{4}{|c|}{ Societal perspective (subsample, patients with participating carer, 35 dyads, $n^{\mathrm{c}}=238$ ) } \\
\hline$\leq 39$ & $116(49)$ & $33,074(19,634 ; 48,016)$ & $34,684(21,516 ; 45,642)$ \\
\hline$>39$ & $121(51)$ & $44,872(21,118 ; 59,309)$ & $46,529(29,503 ; 59,945)$ \\
\hline
\end{tabular}

a 2012 UKE.

${ }^{\mathrm{b}}$ Regression model adjusted for total CMAI score and effects of clustering by repeated measures.

${ }^{\mathrm{c}}$ Number of person follow-ups.

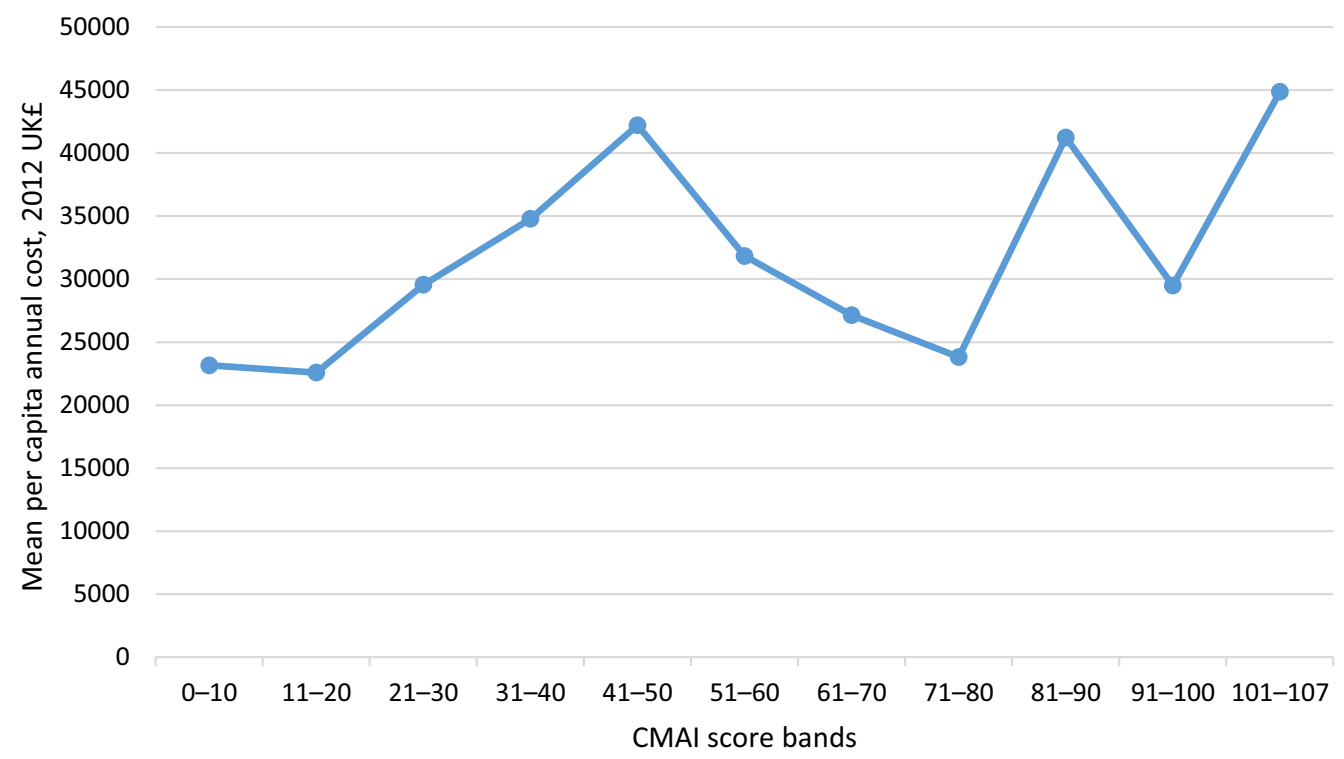

Figure 1. Adjusted* mean per capita annual cost (2012 UKf) by CMAI score bands ( $n=576$ person follow-ups). *Adjusted for effects of clustering by repeated measures within participants.

in costs by demographic variables (age, gender, and marital status).

We found a positive statistically significant $\left(\mathrm{r}_{\mathrm{s}}=0.48, \mathrm{p}<0.01\right)$ correlation between agitation and quality of life (QUALID), while a negative correlation $\left(\mathrm{r}_{\mathrm{s}}=-0.54\right)$ between agitation and symptom management (SM-EOLD) (Table 3). Correlation of agitation with pain (PAINAD) was positive and statistically significant for the sample overall and for those participants with a lower agitation score. The signs are as expected, as lower scores on QUALID represent higher quality of life. There was no statistically significant correlation between agitation and the number of sentinel events.

We estimate the annual expected cost per care home resident with advanced dementia based on 
Table 3. CMAI correlations with physical and psychological symptoms, quality of life in people with advanced dementia (participants $=79$ )

\begin{tabular}{|c|c|c|c|c|c|c|}
\hline VARIABLE & $\begin{array}{c}\text { ALL } \\
\text { (STUDY } \\
\text { ENTRY) }\end{array}$ & $\begin{array}{c}\text { ALL } \\
(\text { WITH } \\
\text { FOLLOW-UP })\end{array}$ & $\begin{array}{c}<39 \\
\text { (STUDY } \\
\text { ENTRY) }\end{array}$ & $\begin{array}{c}<39 \\
(\text { WITH } \\
\text { FOLLOW-UP })\end{array}$ & $\begin{array}{c}\geq 39 \\
\text { (STUDY } \\
\text { ENTRY) }\end{array}$ & $\begin{array}{c}\geq 39(\text { WITH } \\
\left.\text { FOLLOW-UP }{ }^{\mathrm{a}}\right)\end{array}$ \\
\hline SM-EOLD & $-0.52^{b}$ & $-0.53^{\mathrm{b}}$ & $-0.34^{c}$ & $-0.37^{\mathrm{b}}$ & -0.2 & $-0.21^{\mathrm{b}}$ \\
\hline PAINAD (rest) & 0.23 & $0.25^{\mathrm{b}}$ & 0.07 & $0.25^{\mathrm{b}}$ & -0.02 & 0.03 \\
\hline PAINAD (activity) & 0.27 & $0.27^{\mathrm{b}}$ & 0.21 & $0.21^{b}$ & -0.03 & 0.06 \\
\hline QUALID & $0.5^{\mathrm{b}}$ & $0.48^{\mathrm{b}}$ & 0.22 & $0.34^{\mathrm{b}}$ & 0.12 & $0.22^{\mathrm{b}}$ \\
\hline Number of sentinel events & 0.1 & 0.1 & 0.5 & -0.18 & 0 & 0.19 \\
\hline
\end{tabular}

${ }^{a}$ Based on random effects multiple regression accounting for repeated measures.

${ }^{\mathrm{b}}$ Indicates $1 \%$ level of statistical significance.

${ }^{\mathrm{c}}$ Indicates $5 \%$ level of statistical significance.

percentage of residents falling into each CMAI agitation score band is $£ 33,396(0.0069 * £ 23,154+$ $0.2167 * £ 29,557+0.2409 * £ 34,787+0.1975 *$ $£ 42,211+0.1612 * £ 31,829+0.0849 * £ 27,139+$ $0.0572 * £ 23,812+0.0208 * £ 41,236+0.0104 *$ $£ 29,491+0.0034 * £ 44,868=£ 33,396)$ (Table 2). We do not have sufficient participants in each care home to examine the variability between care homes.

We can therefore infer the mean excess cost associated with the increase in CMAI each year, accounting for those with no symptoms on the scale (CMAI agitation score $0-10$ ) as $£ 10,242$ ( $£ 33,396-$ $£ 23,154)$. Thus, on average, agitation as measured by CMAI accounts for $30 \%(£ 10,242 / £ 33,396)$ of health and social care costs each year among people with advanced dementia living in care homes.

If we extrapolate it to the overall number of care home residents with dementia in the UK $(311,730$ according to Dementia UK), which represents about $40 \%$ of the total UK population of PWD older than 65 years, and adjust it by those with clinically significant agitation on the CMAI scale of $40 \%$ (Livingston et al., 2017) and that $34 \%$ of care home residents are in advanced stage of dementia,we predict the excess cost associated with agitation in people with advanced dementia in UK care homes is a total of $£ 435$ million/annum $(£ 10,242 * 311,730 * 0.4 * 0.34)$.

\section{Incorporating informal care costs}

For the subsample of 35 resident carer dyads, 15 (43\%) remained in paid employment and 2 carers had taken early retirement to care for the person with dementia (Table 4). Through the study, all informal carers spent on average 10 days/month providing care with an average of 1.5 hours/day. Two (6\%) carers reported absence from work thus incurring productivity losses, resulting on average in 3.4 hours/month $(\mathrm{SD}=12)$. According to the Office for National Statistics, the median gross weekly earnings for full-time employees were $£ 513$ in 2012 with the high variability based on occupation. Using the human capital approach (Grossman, 1972), and 37.5 mean hours worked/week, we estimate that on average providing informal care resulted in a weekly cost of $£ 184.68$ for those in employment. Considering the level of agitation of a person with dementia in a dyad as binary ( $\leq 39$ and $>39$ ), there was no statistically significant difference in total carer costs. From the societal perspective, annual informal care costs per carer in employment were valued at $£ 9603$, including annual opportunity costs of lost production of $£ 664$ and opportunity costs of lost leisure time (Garber et al., 1996) of $£ 8939$ and excluding double-counting of informal care time or productivity losses. Thus, informal care costs contributed around $29 \%$ to the total societal costs.

\section{Discussion}

\section{Principal findings}

Over half of care home residents with advanced dementia who were nearing end of life showed clinically significant agitation $(\mathrm{CMAI}>39)$ over the 9-month follow-up period of the study.

Per capita costs associated with agitation varied significantly by the number of symptoms experienced as observed on the CMAI scale, this was from $£ 23,154$ for those with no symptoms to $£ 46,674$ for the residents with the most frequent and severe symptoms. We have shown that on average, agitation symptoms may account for $30 \%$ of the health and social care costs each year for those residing in care homes and carry a significant financial burden on the health services. It is important that we consider how costs may not be directly associated with agitation, for example, a person may be agitated because they are in pain or experiencing delirium, both of which may increase costs of care. When accounting for informal care, medical and formal care costs represent just over $70 \%$ of the total 
Table 4. Characteristics and service use by informal carers

\begin{tabular}{|c|c|c|}
\hline \multirow[b]{2}{*}{ VARIABLE } & \multirow{2}{*}{$\frac{\text { BASELINE }}{(n=35)}$} & \multirow{2}{*}{$\frac{\text { LAST VISIT (ALL) }}{(n=34)}$} \\
\hline & & \\
\hline Age, median (IQR) & $62(54-69)$ & \\
\hline Gender: female $n(\%)$ & $24(69)$ & \\
\hline \multicolumn{3}{|l|}{ Relation to patient $n(\%)$} \\
\hline Spouse/partner & $7(20)$ & \\
\hline Son/daughter & $23(70)$ & \\
\hline Other & $4(10)$ & \\
\hline \multicolumn{3}{|l|}{ Marital status $n(\%)$} \\
\hline Married & $20(58)$ & \\
\hline Single & $7(20)$ & \\
\hline Divorced & $6(18)$ & \\
\hline Widowed & $2(5)$ & \\
\hline Number of children (mean, IQR) & $1.27(0-6)$ & \\
\hline Live with patient? $n(\%)$ & $2(6)$ & \\
\hline \multicolumn{3}{|l|}{ How many other informal carers $n(\%)$} \\
\hline 0 & $15(40)$ & $12(36)$ \\
\hline 1 & $11(29)$ & $10(30)$ \\
\hline 2 & $4(11)$ & $5(15)$ \\
\hline 3 & $5(13)$ & $1(4)$ \\
\hline 4 or more & $3(8)$ & $5(14)$ \\
\hline \multicolumn{3}{|l|}{ Level of contribution to care $n(\%)$} \\
\hline $1-20 \%$ & $24(63)$ & $24(70)$ \\
\hline $21-40 \%$ & $9(24)$ & $7(20)$ \\
\hline $41-60 \%$ & $2(5)$ & $1(3)$ \\
\hline $61-80 \%$ & $1(3)$ & $1(3)$ \\
\hline $81-99 \%$ & $2(5)$ & $1(3)$ \\
\hline \multicolumn{3}{|l|}{ Value of informal care } \\
\hline Hours per day providing care (mean, IQR) & $1.43(0 ; 1.75)$ & $1.47(0 ; 2)$ \\
\hline Days per month providing care (mean, IQR) & $10.3(0 ; 16)$ & $10.5(0 ; 20)$ \\
\hline Help, hours/day (mean, IQR) & $0.37(0 ; 1)$ & $0.375(0 ; 1)$ \\
\hline Help, days/month (mean, IQR) & $5.4(0 ; 8)$ & $3.7(0 ; 12)$ \\
\hline Supervision hours/day (mean, IQR) & $0.9(0 ; 1)$ & $1.12(0 ; 1.5)$ \\
\hline Supervision days/month (mean, IQR) & $2.47(0 ; 6)$ & $2.36(0 ; 5)$ \\
\hline Employed for pay $n(\%)$ & $15(38)$ & \\
\hline \multicolumn{3}{|l|}{ Employment hours/week $n(\%)$} \\
\hline $0-10$ & $4(33)$ & \\
\hline $12-20$ & $3(25)$ & \\
\hline $22-30$ & $1(8)$ & \\
\hline $32-40$ & $4(33)$ & \\
\hline Not employed for pay $n(\%)$ & $24(62)$ & \\
\hline \multicolumn{3}{|l|}{ Why not employed? $n(\%)$} \\
\hline Reached retirement age & $13(59)$ & \\
\hline Own health problems & $3(14)$ & \\
\hline Early retirement & $3(14)$ & \\
\hline To care for patient & $2(9)$ & \\
\hline Laid off & $1(5)$ & \\
\hline Paid to care for patient? $n(\%)$ & $1(3)$ & $1(3)$ \\
\hline Hours reimbursed to care for patient, $n=1$ & 30 & 30 \\
\hline \multicolumn{3}{|l|}{ Missed hours of work per day $n=9,(\%)$} \\
\hline No & $7(78)$ & $7(77)$ \\
\hline $1-3$ hours & $1(11)$ & $2(15)$ \\
\hline 4-7 hours & $1(11)$ & $1(8)$ \\
\hline \multicolumn{3}{|l|}{ Missed days of work per month } \\
\hline No & $8(89)$ & $26(76)$ \\
\hline 1 & $1(11)$ & 0 \\
\hline 2 & & $2(13)$ \\
\hline 3 & & $2(13)$ \\
\hline 4 & & $1(7)$ \\
\hline
\end{tabular}


Table 4. Continued

\begin{tabular}{|c|c|c|}
\hline & BASELINE & LAST VISIT (ALL) \\
\hline VARIABLE & $(n=35)$ & $(n=34)$ \\
\hline 6 & & $1(7)$ \\
\hline 10 & & $1(7)$ \\
\hline 30 & & $1(7)$ \\
\hline \multicolumn{3}{|l|}{ Carer service use ${ }^{\mathrm{a}}$ in previous month $n(\%)$} \\
\hline Carers with Hospital admission for $>24$ hours & 0 & $1(3)$ \\
\hline Number of admissions & 0 & 1 \\
\hline Ward admitted & & Oncology \\
\hline Nights on surgery & 0 & 2 \\
\hline Hospitalizations $<24$ hours & $1(3)$ & $1(3)$ \\
\hline Care from doctor, PT, psychologist, other HCP & $14(38)$ & $10(34)$ \\
\hline \multicolumn{3}{|l|}{ Number of visits for each below } \\
\hline GP & $11(62.5)$ & $8(73)$ \\
\hline Geriatrician & $1(6)$ & 0 \\
\hline Neurologist & 0 & 0 \\
\hline Psychiatrist & 0 & 0 \\
\hline Physiotherapist & $4(25)$ & 0 \\
\hline Occupational Therapist & 0 & 0 \\
\hline Social worker & 0 & $1(9)$ \\
\hline Psychologist & 0 & $6(18)$ \\
\hline Other & $8(50)$ & $3(50)$ \\
\hline
\end{tabular}

${ }^{\mathrm{a}}$ Twenty-nine out of thirty-five carers completed the relevant section in resource use questionnaire.

care costs, suggesting that the contribution of informal care (29\% in our study) is often underestimated in health economic studies which mainly adopt the health and social care perspective only in economic analyses (NICE, 2013).

Other studies have previously considered the association between costs of care in PWD. Zhu et al. (2015) and Konig et al. (2014) found no significant changes in costs, but Leicht et al. (2013) found in a mixed sample of care home and community-dwelling PWD that a severe cognitive impairment was significantly associated with higher healthcare costs. Studies (Schwarzkopf et al., 2011; Murman et al., 2009) that have reported a similar positive association had dementia cohorts residing primarily in the community and thus excluded costs of care home stays.

There was no statistically significant difference in mean costs per resident by sociodemographic (age, gender, and marital status) and clinical (comorbidities) confounders.

This may be partially explained by participants being in the severe stages of dementia who, on average, resided in the care home for 3 years and had an average of seven comorbidities. Those participants with agitation in the upper bands of the CMAI scale utilize more health services possibly because (a) care home staff are less equipped to address their symptoms in the care home setting and (b) they are more physically frail and unwell and may, for example, be at higher risk of delirium which may be associated with agitation, as evidenced by the correlation of agitation with symptom management.

Several previous studies have examined the relationship between behavioral symptoms and costs of care associated with dementia and found a positive relationship. Most, however, used the Neuropsychiatric Inventory agitation score and primarily utilized US or Scandinavian data (Murman et al., 2009; Jönsson et al., 2006).

With a wide variability in costs by CMAI, we infer that cost savings will occur if symptoms are reduced. As care home staff may be time constrained or lack sufficient training to provide adequate control of prevalent symptoms, they may welcome input from other healthcare professionals (HCPs). While it is estimated that $86 \%$ of dementia care home residents are agitated with $40 \%$ having clinically significant symptoms on the CMAI scale, evidence suggests there may often be insufficient input from external healthcare providers. In a study involving 2 case studies and a survey of 180 nursing homes, Seymour et al. (2011) reported variable GP support for care home residents, including reluctance to prescribe appropriate medication, lack of out of hours support, and a lack of access to training. In one of the largest studies of end-of-life care in nursing homes in the UK, Kinley et al. (2014) found provision of healthcare from outside the homes was variable. Recently, we (Sampson et al., 2017) concluded that service provision was not tailored to the needs of people with advanced 
dementia with limited access to specialist care for the current study sample.

Even when PWD are residing in the care home, their informal carers alleviate some of the burden placed on services. According to 2015 data, in the UK, some 3.6 million of the 5.0 million carers of older people provide less than 10 hours of care/week, while the remainder provide more; (90\%) of these carers are aged under 65 , and $67 \%$ are in employment (Brimblecombe et al., 2016) and $21 \%$ of those in employment had to cut their working hours or leave employment to care for PWD (Public Health England, 2018). There are currently no UK studies that incorporate the monetary value of informal care based on actual working time when caring for persons with dementia residing not in the community setting, but at a care home. While in our cohort the productivity losses were comparatively low compared to informal and total care costs, they should be incorporated in the health economic studies where data are available.

\section{Limitations}

The model provides valid inferences under the assumption that data are missing at random. The normality assumptions of the residuals were investigated using residual plots. Our dataset did not permit a statistical analysis for identification of predictors of formal care costs. We used a selected sample of people with severe dementia, and thus there was little heterogeneity in our sample in the degree of the residents' physical and mental impairment. Moreover, the data did not provide care home-level characteristics. There may be a selection bias in the participating informal carers who consented to take part in this study. While the sample size was relatively small preventing further stratification by individual CMAI scores or mortality, for the UK study of people with advanced dementia the dataset is unique, representative, and relatively large.

\section{Directions for further research}

Interventions aimed at alleviating symptoms which may lead to agitation in advanced dementia, such as treatment of pain according to the stepwise protocols can be effective (Husebo et al., 2011). Economic evaluation of such interventions should use a standard outcome of quality-adjusted life years, using measures such as DEMQOL (Ratcliffe et al., 2017) in a clinical trial, to allow for costeffectivenessanalysis.

Lower birth rates, increasing childlessness, number of divorces, and number of children who live far from their parents as well as a rise of employment rates among women will lead to a decrease in the potential availability of informal carers. With stagnating informal care provision, an increase in the number of PWD with unpredictable life expectancy, many with agitation, costs will continue to increase and more pressure will be placed on care homes. Services, including those for end of life, will need to adapt to meet these challenges and take into account symptoms such as agitation.

\section{Conflict of interest}

None.

\section{Source of funding}

The Compassion Program was funded by Marie Curie Care [Grant reference: MCCC-FPR-11].

\section{Description of authors' role}

ELS, SM, MK, GL, IN, RO, and LJ developed the research program and obtained funding. $\mathrm{BC}, \mathrm{SD}$, $\mathrm{NK}, \mathrm{KM}$, and VV collected data, formulated research questions, managed and interpreted the data. VV contributed to data analysis. SM advised on health economics throughout the program and this current analysis. ABG conducted developed this study, statistical analysis, carried out the analysis and wrote this paper. All authors contributed to the development of the manuscript.

\section{Acknowledgments}

We thank our researchers, Sharon Scott, Dr Jane Harrington, Dr Margaret Elliott, and Dr Kathryn Lord, our study participants, and the care homes that supported the project.

\section{References}

Alzheimer's Disease International (2010). World Alzheimer Report 2010, the global economic impact of dementia. Alzheimer's Disease International.

Alzheimer's Society (2014). Dementia UK, update, 2nd edn. Alzheimer's Society.

Beecham, J. and Knapp, M.R. (1992). Costing psychiatric intervention. In: G. Thornicroft, C.R. Brewin and J. Wing (Eds.), Measuring Mental Health Needs. London: Gaskell.

Brimblecombe, N., Fernandez, J.L., Knapp, M., Rehill, A. and Wittenberg, R. (2016). Unpaid Care in England, Future Patterns and Potential Support Strategies. Downloaded from http://eprints.lse.ac.uk/90215/1/.

Charlson, M.E. (1987). Studies of prognosis: progress and pitfalls. Fournal of General Internal Medicine, 2, 359-361. 
Cohen-Mansfield, J., Marx, M.S. and Rosenthal, A.S. (1989). A description of agitation in a nursing home. The Fournals of Gerontology, 44, M77-M84.

Curtis, L. (2012). Unit Costs of Health and Social Care 2012. Canterbury: Personal Social Services Research Unit, University of Kent.

Department of Health (2013). 2011-2012 NHS Reference Costs. London: Department of Health. Downloaded from https://www.gov.uk/government/publications/nhsreference-costs-financial-year-2011-to-2012.

Desgagne, A., Castilloux, A.M., Angers, J.F. and LeLorier, J. (1998). The use of the bootstrap statistical method for the pharmacoeconomic cost analysis of skewed data. Pharmacoeconomics, 13, 487-497.

Etkind, S.N. et al. (2017). How many people will need palliative care in 2040? Past trends, future projections and implications for services. BMC Medicine. doi: 10.1186/ s12916-017-0860-2.

Garber, A.M., Weinstein, M.C., Torrance, G.W. and Kamlet, M.S. (1996). Theoretical foundations of costeffectiveness analysis. In M.R. Gold, J.E. Siegel, L.B. Russel and M.C. Weinstein (Eds.), Cost-Effectiveness in Health and Medicine (pp. 25-53). New York: Oxford University Press.

Gold Standards Framework (2008). The Gold Standards Framework. NHS End of Life Care Programme, http://www .goldstandardsframework.org.uk/ (accessed 11 October 2008).

Grossman, M. (1972). On the concept of health capital and the demand for health. Fournal of Political Economy, 80, 223-585.

Handley, M. et al. (2014). Living and dying, responsibility for end-of-life care in care homes without on-site nursing provision - a prospective study. Health $\mathcal{E}$ Social Care in the Community, 22, 22-29.

Health Economics Research Centre, University of Oxford for the Alzheimer's Research Trust (2010) Dementia 2010: The economic burden of dementia and associated research funding in the United Kingdom.

Husebo, B.S., Ballard, C., Sandvik, R., Nilsen, O.B. and Aarsland, D. (2011). Efficacy of treating pain to reduce behavioural disturbances in residents of nursing homes with dementia: cluster randomised clinical trial. British Medical fournal, 343, d4065.

Jakobson, E., Avari, J. and Kalayam, B. (2015). Nonpharmacologic interventions for treatment of agitation in dementia in nursing home residents. The American fournal of Geriatric Psychiatry, 23, S139-S140.

Jones, L. et al. (2012). CoMPASs: IOn programme (care of memory problems in advanced stages of dementia: improving our knowledge): protocol for a mixed methods study. British Medical fournal Open, 2, e002265.

Jönsson, L. et al. (2006). Determinants of costs of care for patients with Alzheimer's disease. International fournal of Geriatric Psychiatry, 21, 449-459.

Kiely, D.K., Volicer, L., Teno, J., Jones, R.N., Prigerson, H.G. and Mitchell, S.L. (2006). The validity and reliability of scales for the evaluation of end-of-life care in advanced dementia. Alzheimer Disease and Associated Disorders, 20, 176-181.
Kinley, J. et al. (2014). The provision of care for residents dying in U.K. nursing care homes. Age and Ageing, 43, 375-379. doi: 10.1093/ageing/aft158.

Konig, H.H. et al. (2014). The costs of dementia from the societal perspective, is care provided in the community really cheaper than nursing home care? fournal of the American Medical Directors Association, 15, 117-126.

Leicht, H. et al. (2013). AgeCoDe Study Group, predictors of costs in dementia in a longitudinal perspective. PLoS One, 8, e70018.

Livingston, G., Katona, C., Roche, B., Guilhaume, C. and Rive, B. (2004). A dependency model for patients with Alzheimer's disease, its validation and relationship to the costs of care - the LASER AD study. Current Medical Research and Opinion, 20, 1007-1016.

Livingston, G. et al. (2017). Prevalence of and associations with agitation in residents with dementia living in care homes, MARQUE cross-sectional study. BMF Open, 3, 171-178. doi: 10.1192/bjpo.bp.117.005181.

Luengo-Fernandez, R., Leal, J. and Gray, A. (2015). UK research spend in 2008 and 2012, comparing stroke, cancer, coronary heart disease and dementia. BMF Open, 5, e006648. doi: 10.1136/bmjopen-2014-006648.

Matthews, F. et al. (2013). A two-decade comparison of prevalence of dementia in individuals aged 65 years and older from three geographical areas of England, results of the Cognitive Function and Ageing Study I and II - on behalf of the Medical Research Council Cognitive Function and Ageing Collaboration. The Lancet, 382, 1405-1412. doi: 10.1016/S0140-6736(13)61570-6.

Moore, K.J. et al. (2017). Experiences of end of life amongst family carers of people with advanced dementia, longitudinal cohort study with mixed methods. BMC Geriatrics, 17, 135.

Morris, S. et al. (2015). Monetary costs of agitation in older adults with Alzheimer's disease in the UK, prospective cohort study. British fournal of Psychiatry Open, 5, e007382. doi: 10.1136/bmjopen-2014-007382.

Murman, D, High, R, Charlton, M. and Mclaughlin, T. (2009). Predicting costs of care for unique dependence levels in patients with Alzheimer's disease. Alzheimers $\mathcal{E}$ Dementia, 5, P408. doi: 10.1016/j.jalz.2009.04.994.

National Council for Palliative Care (2015). Published July 2015 by the National Council for Palliative Care.

National Institute for Health and Care Excellence (NICE) (2013). Guide to the methods of technology appraisal 2013.

ONS, Office for National Statistics. Annual Survey of Hours and Earnings (2013). London. Downloaded from https://www.ons.gov.uk/employmentandlabourmarket/ peopleinwork/earningsandworkinghours/bulletins/ annualsurveyofhoursandearnings/2013results\#earningsby-occupation.

ONS, Office for National Statistics Deaths registered in England and Wales (series DR) (2016). Downloaded from https://www.ons.gov.uk/peoplepopulationandcommunity/ birthsdeathsandmarriages/deaths/bulletins/ deathsregisteredinenglandandwalesseriesdr/2016.

Prince, M. et al. (2014). Demenita UK, Update Second Edition report produced by King's College London, the London School of Economics for the Alzheimer's Society. 
Prince, M., Wimo, A., Guerchet, M., Ali, G-C., Wu, Y-T. and Prina, M. (2015). World Alzheimer Report 2015. The Global Impact of Dementia. An analysis of prevalence, incidence, costs and trends. London, Alzheimers Diseases International.

Public Health England (2018). Guidance Dementia, applying All Our Health, Updated 23 January 2018.

Ratcliffe, J. et al. (2017). An empirical comparison of the EQ-5D-5L, DEMQOL-U and DEMQOL-Proxy-U in a post-hospitalisation population of frail older people living in residential aged care. Applied Health Economics and Health Policy, 15, 399-412.

Reisberg, B. (1998). Functional assessment staging (FAST). Psychopharmacology Bulletin, 24, 653-659.

Ridder, H.M., Stige, B., Qvale, L.G. and Gold, C. (2013). Individual music therapy for agitation in dementia, an exploratory randomized controlled trial. Aging $\mathcal{E}$ Mental Health, 17, 667-678.

Rizzuto, D., Bellocco, R., Kivipelto, M., Clerici, F., Wimo, A. and Fratiglioni, L. (2012). Dementia after age 75 , survival in different severity stages and years of life lost. Current Alzheimer Research, 9, 795-800.

Rubin, D.B. (1987). Multiple Imputation for Nonresponse in Surveys. New York: Wiley.

Sampson, E.L. et al. (2017). Living and dying with advanced dementia, a prospective cohort study of symptoms, service use and care at the end of life. Palliative Medicine, 32, 668-681. doi: 10.1177/0269216317726443.

Schwarzkopf, L. et al. (2011). Costs of care for dementia patients in community setting, an analysis for mild and moderate disease stage. Value Health, 14, 827-835.

Seymour, J.E., Kumar, A. and Froggatt, K. (2011). Do nursing homes for older people have the support they need to provide end-of-life care? A mixed methods enquiry in England. Palliative Medicine, 25, 125-38. doi: 10.1177/ 0269216310387964.
Sleeman, K.E., Ho, Y.K., Verne, J., Gao, W. and Higginson, I.J. (2014). Reversal of English trend towards hospital death in dementia, a population based study of place of death and associated individual and regional factors, 2001-2010. BMC Neurology, 14, 59. doi: 10.1186/14712377-14-59.

StataCorp, Stata Statistical Software (2014). Release 13. College Station, TX, USA: StataCorp LP.

Thompson, S.G. and Barber, J.A. (1999). The distribution of health care costs and their statistical analysis for economic evaluation. Fournal of Health Services Research and Policy, 4, 255.

van den Berg, B., Brouwer, W.B. and Koopmanschap, M.A. (2004). Economic valuation of informal care. An overview of methods and applications. European fournal of Health Economics, 5, 36-45.

Warden, V., Hurley, A.C. and Volicer, L. (2003). Development and psychometric evaluation of the Pain Assessment in Advanced Dementia (PAINAD) scale. Fournal of the American Medical Directors Association, 4, 9-15.

Weiner, M.F., Martin-Cook, K., Svetlik, D.A., Saine, K., Foster, B. and Fontaine, C.S. (2000). The quality of life in late-stage dementia (QUALID) scale. Fournal of the American Medical Directors Association, 1, $114-116$.

Wimo, A. and Winblad, B. (2003). Resource utilization in dementia, RUD Lite. Brain Aging, 3, 48-59.

Wolstenholme, J., Fenn, P., Gray, A., Keene, J., Jacoby, R. and Hope, T. (2002). Estimating the relationship between disease progression and cost of care in dementia. British fournal of Psychiatry, 181, 36-42.

Zhu, C.W. et al. (2015). Medicare utilization and expenditures around incident dementia in a multiethnic cohort. The fournals of Gerontology. Series A, Biological Sciences and Medical Sciences, 70, 1448-1453. 